\title{
A study to assess the knowledge on computer aided learning programs among students attending Kenya Medical Training College, Nairobi campus
}

\author{
Salim M. Omambia \\ Kenya Medical Training Centre, P.O. Box 30195-00100 \\ Mutiso N. Kivungi \\ Kenya Medical Training Centre, P.O. Box 30195-00100
}

\begin{abstract}
Computer Assisted Learning (CAL) is a method of acquiring knowledge using electronic media which is gaining recognition among students. This requires access to computers and considerable awareness on information technology. Studies the world over have also highlighted the roles of computer as an instructional material in the classroom particularly in regard to assisting in enriching the teaching learning. Objective: The objective of this study sought to assess the knowledge on computer aided learning programs among students attending Kenya Medical Training College, Nairobi campus Methods: This study was a descriptive research study, the targeted population of the study were 4,490 KMTC Nairobi Campus students, and the sample technique used was random sampling. Data was collected from respondents by use of a questionnaire, and the analysis was based on the findings obtained from the questionnaire. Data presentation was in form of descriptive statistics such as frequency distribution, percentages, pie charts, bar graphs and tables. Results and Discussions: The data from the knowledge on computer aided learning programs were summarized in three main evaluation areas targeting the ICT access, student perception and frequency of computer use. From the findings, there was a significant association between knowledge and perception of ICT and participants sex $(p=0.001)$. Females were more likely to have positive responses compared to males (72.3 versus $49.9 \%)$. Access point was also associated with perception $(p=0.005)$. Accessing computers in the computer lab was associated with higher Likert scale responses. The perception of CAL among the students was closely associated with how much the students access the CAL and their knowledge on computers at KMTC. $184(97.4 \%)$ of the participants reported that computers were available in college, and $138(74.6 \%)$ said that the access point were the computer laboratory. These findings were in line with the Kenyan Government agenda for increasingly acquiring computers to equip all the public schools and institution of higher learning according to the Ministry of Education Science and Technology Sessional Paper, (2012). Conclusions: Based on the results and discussions, among the main problems that key informants described during the study, regardless of the fact that there was a significant association between knowledge and perception of ICT and participants gender, female students had more access to CAL facilities as compared to the male students. Hence the female students at KMTC had more knowledge as compared to the male students with regards to CAL Recommendations: KMTC in collaboration with the MOE needs to come up with a standardised guideline for CAL implementation
\end{abstract}

Keywords: KMTC- Kenya Medical Training Collage, CAL- Computer Aided Learning, ICT Information Communication and Technology, MOE- Ministry of Education (Kenya), BRACBangladesh Rural Advancement Committee 


\section{INTRODUCTION}

Computer Aided Learning (CAL) was one of the most commonly used acronyms within education. It was difficult to say exactly when the term CAL was first employed, however since the mid-1980s CAL has been increasingly used to describe the use of technology in teaching. The computer-aided learning program is an endeavor to make the content of textbooks easier, interactive and more stimulating. Research has shown that some of the contents, irrespective of the subject, are difficult to comprehend. To assist teachers interact better with students BRAC started the CAL program in 2004, were computers are used as a medium of teaching [2]

Information and communication technology infrastructure was one of the key priorities of education policies of countries all over the world over the past decades In the EU, for instance, the European Commission developed several action plans which aimed at implementing and integrating ICT into primary schools, secondary schools, colleges and universities. An example of such an action plan was the CAL Learning Initiative [4].

This policy was adopted by the European Commission in the year 2000 with the primary purpose of improving the quality of learning by increasing Students access to ICT facilities in schools. As a result, each European Member State developed national strategies to foster the integration and use of ICT in education. The core objective of most of these strategies was on investing public resources in the implementation of ICT in education. Overall, the results of these policies are positive for the EU.

CAL played an important role and E-learner are individuals who uses the online material for learning purposes, they fairly independent, reads in their comfortable time and space .On the other hand E-teaching is said to be a directives given via an electronic media in both virtual and face to face classrooms and E-teaching enable online communications and online sharing of course material. E-learning can be used in medical education to improve the efficacy of academic deliverance and make the learning sessions more captivating and retainable Developing countries are growing in the consumption of computer and internet based learning compared to the usage in the last decade. The major challenge faced by the growing countries is availability of computers and access to internet, financial support in terms of administration and faculty time and training [11]

Internet and software-based platforms (e-learning) have gained popularity as teaching tools in medical education. Technology-assisted education is used in graduate medical education across a variety of content areas and participant types. Knowledge gain was the predominant outcome measured. The majority of studies that directly compared knowledge gains in technology-assisted education to traditional teaching methods found technology-assisted education equal or superior to traditional teaching methods, though no "best methods" or "best use" was found within those studies. Only three articles were specific to Emergency Medicine, suggesting further research in our specialty is warranted (J surg, 2015).

While technologies such as virtual instruction and intelligent tutoring offer great promise, unless the challenges that are associated with implementing them are fully understood and addressed their failure is almost surely guaranteed. To date, there is little evidence that digital learning can be implemented at scale in a way that improves outcomes for disadvantaged students [10]

\section{Study Purpose}

The aim of the study was to assess the knowledge on computer aided learning programs among students attending Kenya Medical Training College, Nairobi campus 


\section{Limitations of the Study}

Due to limited time and resources the researcher did not expound on all the key variables in knowledge on CAL, other variable will be subject for another study. Overall process was time consuming and financially demanding despite a work plan and budget. Also the issue of obtaining letter for permission to collect data from KMTC was time consuming and needed a lot of effort

\section{Delimitations of the Study}

This study concentrated only on Kenya Medical Training Collage. The study focused on assessing the knowledge on computer aided learning programs at KMTC Nairobi Campus. The variable aspects considered included; Perceptions, Access and frequency of computer use. Other factors affecting the knowledge of CAL, may act as confounders not tackled in this study and were to be a subject of follow up studies.

\section{Significance of the Study}

Research has showed that the CAL programme brings positive changes in schools. Students are more motivated and can learn effectively through CAL materials and the teachers feel more comfortable in managing a class. The teachers of CAL schools were given training on computer operation and CAL materials. . Studies on computer-aided instruction and web-based learning have left many questions unanswered about the most effective use of technology-assisted education in graduate medical education. Technology-assisted education has been used in graduate medical education across a variety of content areas and participant types. Knowledge gained is a predominant outcome measured. The majority of studies that directly compare knowledge gains in technology-assisted education to traditional teaching methods found out that technology-assisted education equal or superior to traditional teaching methods, though no "best methods" or "best use" was found within those studies (Zhang, 2017).

To illustrate the chasm and indicate the importance of CAL, the researcher embarked on a study on the knowledge on computer aided learning programs among students attending Kenya Medical Training College, Nairobi campus to describe an idealized scenario in which each stakeholder's needs are supported by an integrated health IT environment. The study identified the gaps preventing such a reality today and present associated policy recommendations that serve as a blueprint for critical actions that would enable the education sector to cross the current health IT chasm by leveraging systems and information to routinely deliver high-value care. 


\section{Conceptual Framework}

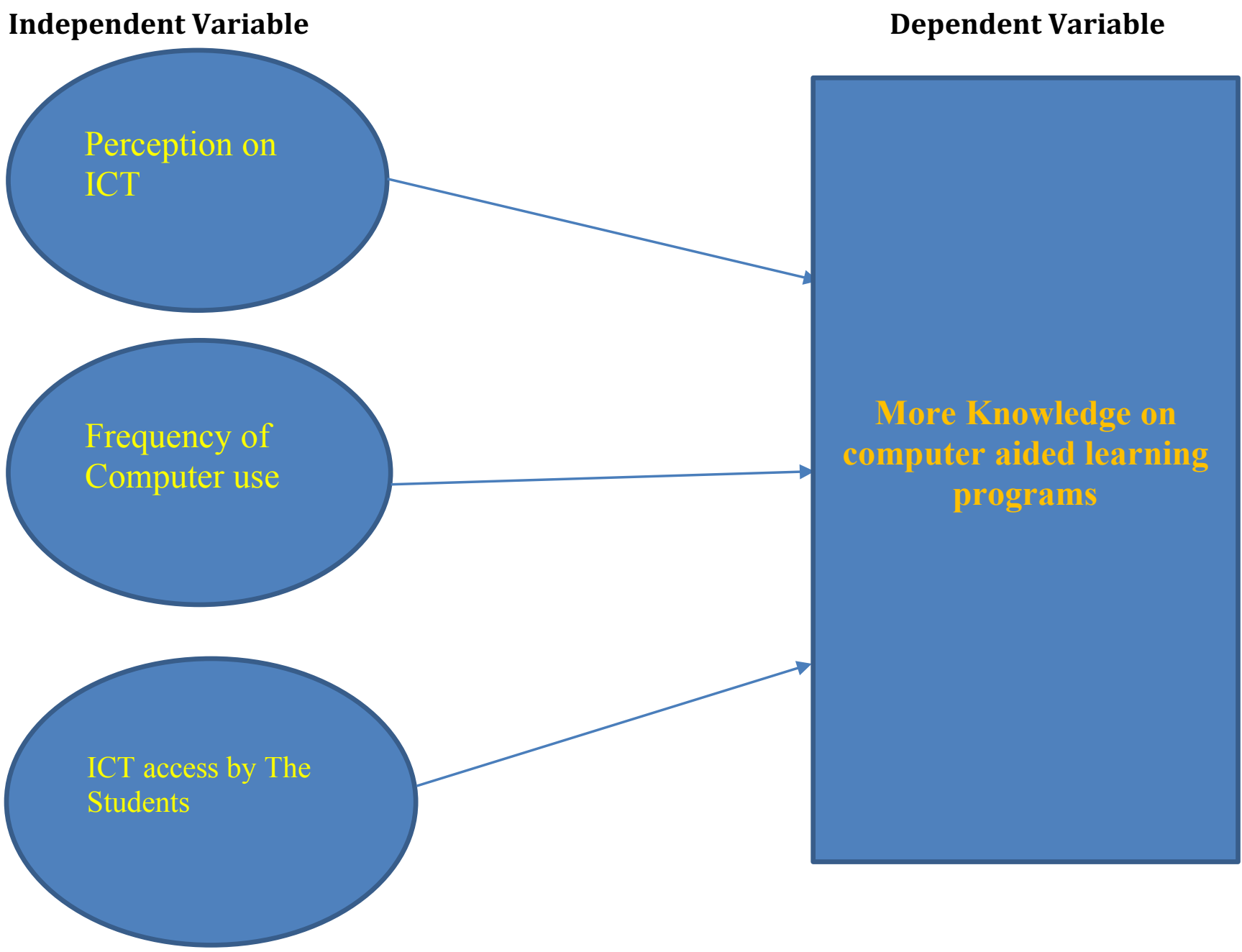

Figure 1: Conceptual Framework

\section{MATERIALS AND METHODS}

The study was conducted in Kenya Medical Training College Nairobi Campus situated in Nairobi County and used a descriptive research design. Descriptive research was used to obtain information concerning the current status of the phenomena to describe what exists, with respect to variables or conditions in a situation. Descriptive research aimed at gathering data without any manipulation of the research context and it is non-intrusive and deals with naturally occurring phenomena, where the researcher has got no control over the variables (Mugenda, 2008).

The targeted population were the 4,490 KMTC Nairobi Campus students. The study investigated selected students and faculties in KMTC Nairobi Campus. The Nairobi Campus is the biggest and considered the epitome in the country and thus has the most staff and students, being at the headquarters it is expected that it is the most equipped. The scope was deemed appropriate due to the fact that with rise in technology, urban areas and cities in specific embrace it with ease. The scope was also significant to minimize expenses which would otherwise be incurred outside the researchers' residential city.

The researcher used random sampling and a random sample is a sample that is chosen randomly. It could be more accurately called a randomly chosen sample. Random samples are used to avoid bias and other unwanted effects. A simple random sample was chosen in such a way that every set of individuals had an equal chance to be in the selected sample. The 
sampling method used was ascertain representativeness of the general population. Based on the representativeness of the technique used, it permitted the researchers to draw conclusions as a representation for the entire population (Mugenda, 2008).

From the study the independent variables were the perception on ICT, Frequency of computer use and ICT Access by the students in the assessment the knowledge on computer aided learning programs at KMTC. Since an independent variable refers to the status of the presumed cause whereas the dependent variable is the presumed effect. Effectual assessment of the knowledge on computer aided learning programs among students attending Kenya Medical Training collage was the dependent variable.

Data analysis was done using SPSS, Ms Excel and Ms Word software's with univariate, bivariate and thematic statistics being utilized. Univariate analysis commonly involved reporting measures of central tendency, this involves describing the way in which quantitative data tend to cluster around some value. Bivariate analysis is one of the simplest forms of quantitative (statistical) analysis. It involves the analysis of two variables for the purpose of determining the empirical relationship between them in order to see if the variables are related to one another, it is common to measure how those two variables simultaneously change together Bivariate analysis can be helpful in testing simple hypotheses of association. Thematic statistics convert conversations into themes or codes for qualitative statistics

Before data collection, a permit was sort from the Kenya Medical Training College and the Medical Education department Kenya Medical Training College. After production of the research permit, permission to carry out research was granted by the research and ethics board team. The Administrators, staff and the support staff of the departments selected were informed in advance concerning the visits and for data collection in their respective departments and offices. The researcher ensured that confidentiality was paramount and that the information obtained was used only for the purpose of this study

\section{RESULTS}

During the study a total of 189 KMTC student were approached, and participated in the survey through completing and returning the study questionnaire. 
Figure 1 shows the sex distribution of participants in the study.

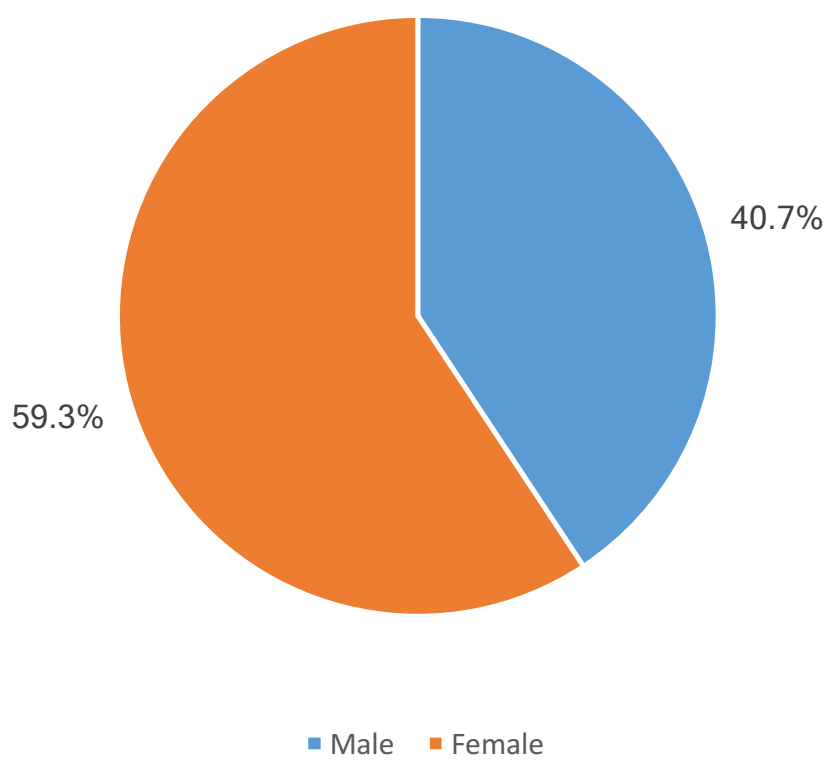

Table 1 shows student reported availability and access to ICT infrastructure within KMTC

Departmental office

Computer lab

Classroom

0

Internet connection in college

Daily

Weekly

Monthly

Never

73

39.2

Frequency of instructor use of electronic teaching devices during lessons

Once a week

Monthly

Yearly

5

Never

21

Internet connection in college

Yes

No

57

Type of internet connection

Prepaid modem

Internet server

Purpose of internet use

Communicate with friends and family

Communicate with teachers or students on college related matters 
Do you have any other electronic devices within college?

Yes

No

Use of other electronic devices in college

Entertainment

Access broadcast lessons

\section{STUDENT PERCEPTION OF ICT EXPERIENCE IN TEACHING AND LEARNING}

Lau, and Bates [7]. Earlier studies showed that multimedia Computer Assisted Learning enhances the experience of both teaching and learning and it is the easiest method available for updating and use at ease Medical education is constantly increasing at a rapid speed and to keep There were 77 (40.7\%) males and 112 (59.3\%) females in the study yielding a male to female ratio of 2: 3 .

Figure 1: Sex distribution of KMTC students enrolled in survey

There were 92 (48.7\%) third year students among the participants, 66 (34.9\%) second year students and the remaining participants were first years as shown in Figure 2.

Figure 2: Distribution of participating KMTC students according to year of study

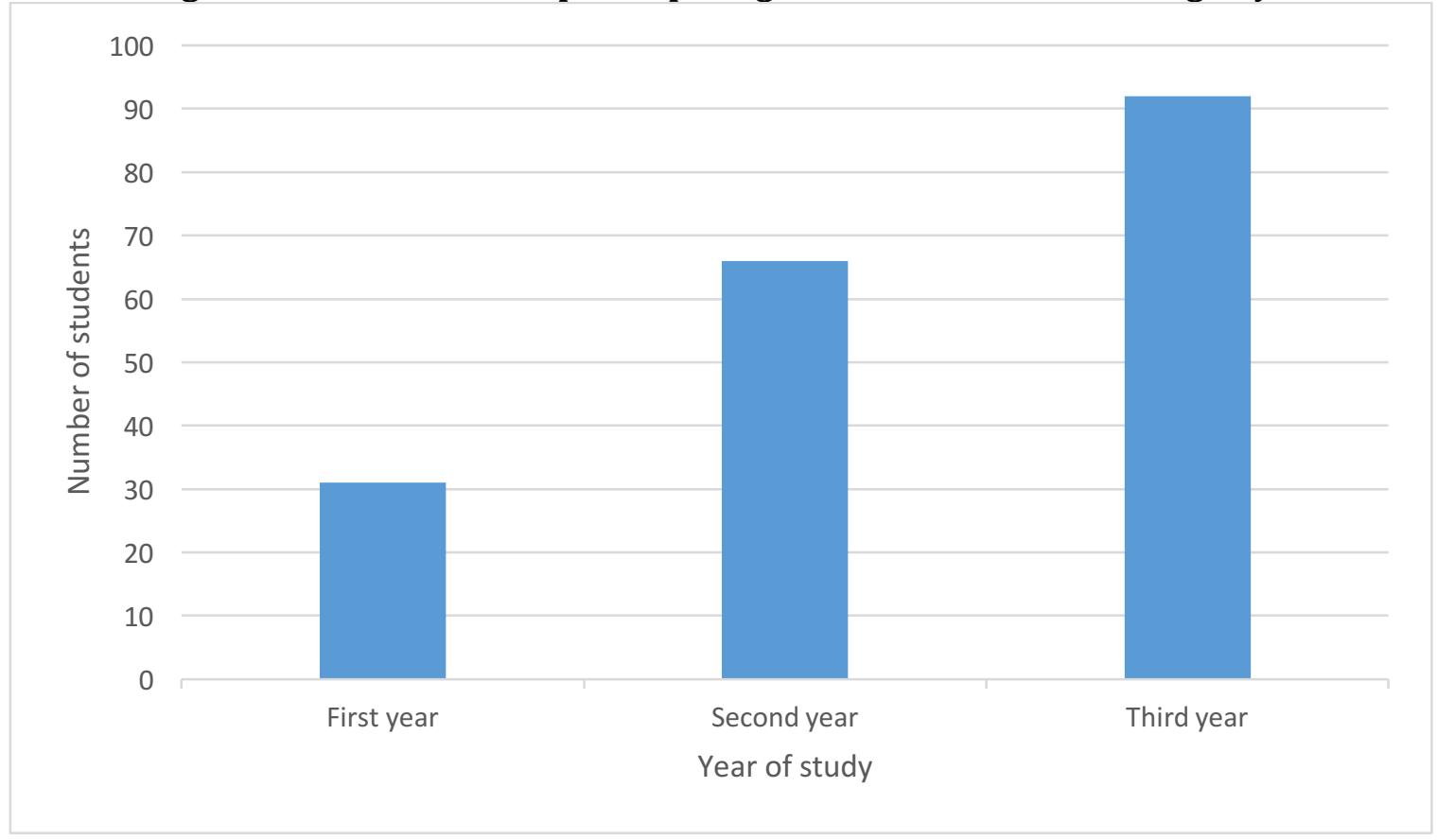

Table 1 shows student reported availability and access to ICT infrastructure within KMTC. According to [6] the European Union termed information and communication technology infrastructure as a key priority of Education Policies of countries all over the world. From our study majority 184 (97.4\%) participants reported that computers were available in college, and $138(74.6 \%)$ said that the access point was the computer laboratory. These findings are in line with the Kenyan Government agenda that has increasingly acquired computers to equip all the public schools and institution of higher learning according to [3]. 
Approximately two thirds (69.5\%) of participants had internet access in college, and 92.8\% had internet server connection as opposed to paid modem connectivity. At least one-half $(56.7 \%)$ of participants reported that they used internet for searching information. Seventy percent of participants reported that they had other electronic devices in college. [8] Perceived that, the technological capabilities make the student to reach as well as to educate a lot more learners. The web access also allow the students to get different educational sources from all more than the globe, thus creating the globe like a classroom of learning. Making Learning accessible almost anywhere a computer can be located [1]. Also, the self-pacing learning concept eliminates the need for group instruction and scheduling Along with flexibility of schedules comes the cost-effectiveness of using CAL over traditional. From our study this could be achieved with a few challenges where we noted that Computers were not accessible within the classrooms were $73(39.2 \%)$ participant had no accesses to internet connection in college, and for those who accessed them mostly had weekly (27.4\%) access. About (59.9\%) participants reported that teachers used electronic devices to aid teaching on a weekly basis. The major challenge as postulated by [11] is that developing countries are faced by lack of availability of computers and access to internet, financial support in terms of administration and faculty time and training.

Table 1: ICT access among KMTC students

\begin{tabular}{lll}
\hline & $\begin{array}{l}\text { Frequency } \\
(\mathrm{n})\end{array}$ & $\begin{array}{l}\text { Percent } \\
(\%)\end{array}$ \\
\hline Computers availability in college & & \\
Yes & 184 & 97.4 \\
No & 5 & 2.6 \\
\hline
\end{tabular}

Frequency of access to computers

The upcoming doctors and established physicians in par with the competitive world. CAL has become a necessary tool and the platform most commonly used is Learning Management System (LMS).LMS simplifies the assessment, evaluation and supervision of the content delivered via E-learning

Most students from the study either strongly agreed (66\%) or agreed $(29 \%)$ that learning computer would improve the presentation work in class and that computers increase the level of use of software applications (54\% and 37\%, respectively). Similarly, high agreement was reported for the response items: I have improved my skills on computers; and students learn better through computers (Table 2). This findings are in agreement with what (Zhang, 2017). Said about the CAL programme, that they bring positive changes in schools. Students are more motivated and can learn effectively through CAL materials and the teachers feel more comfortable in managing a class. The teachers of CAL schools are given training on computer operation and CAL materials. The teachers then teach their students incorporating CAL and using those materials in the classes. Studies on computer-aided instruction and web-based learning have left many questions unanswered about the most effective use of technologyassisted education in graduate medical education. Technology-assisted education is used in graduate medical education across a variety of content areas and participant types. Knowledge gain is a predominant outcome measured. The majority of studies that directly compare knowledge gains in technology-assisted education to traditional teaching methods found out that technology-assisted education equal or superior to traditional teaching methods, though no "best methods" or "best use" was found within those studies 
Table 2: Student perception of ICT experience in teaching and learning

\begin{tabular}{|l|l|l|l|l|l|}
\hline & $\mathrm{SD}$ & $\mathrm{D}$ & $\mathrm{U}$ & $\mathrm{A}$ & $\mathrm{SA}$ \\
\hline The college promotes computer use & $18(10)$ & $24(13)$ & $24(13)$ & $64(34)$ & $58(31)$ \\
\hline $\begin{array}{l}\text { There is increased instructional materials in the } \\
\text { internet }\end{array}$ & $11(6)$ & $22(12)$ & $37(20)$ & $73(39)$ & $43(23)$ \\
\hline $\begin{array}{l}\text { Learning computer would improve the } \\
\text { presentation of work in class }\end{array}$ & $3(2)$ & $0(0)$ & $6(3)$ & $55(29)$ & $124(66)$ \\
\hline $\begin{array}{l}\text { Teachers use the multimedia technology (use } \\
\text { computers and other materials) }\end{array}$ & $2(1)$ & $14(7)$ & $30(16)$ & $86(46)$ & $55(29)$ \\
\hline $\begin{array}{l}\text { There is provision of professional support } \\
\text { through the internet (online learning) }\end{array}$ & $20(11)$ & $20(11)$ & $36(19)$ & $61(32)$ & $51(27)$ \\
\hline Students learn better through computers & $6(3)$ & $14(8)$ & $39(21)$ & $70(38)$ & $55(30)$ \\
\hline $\begin{array}{l}\text { Computers increase the level of software } \\
\text { applications use e.g. word, access, excel }\end{array}$ & $3(2)$ & $2(1)$ & $12(6)$ & $70(37)$ & $102(54)$ \\
\hline I have improved my skills on computers & $12(6)$ & $24(13)$ & $21(11)$ & $57(30)$ & $75(40)$ \\
\hline
\end{tabular}

Mean and median scores on perceived role of computers in teaching and learning

\begin{tabular}{|c|c|c|c|c|c|c|}
\hline & & & & Lower & & Upper \\
\hline Variable & $\mathrm{N}$ & Mean & SD & IQR & Median & $\mathrm{IQR}$ \\
\hline The college promotes computer use & 188 & 2.6 & 1.3 & 2 & 3 & 4 \\
\hline $\begin{array}{l}\text { There is increased instructional materials in the } \\
\text { internet }\end{array}$ & 186 & 2.6 & 1.1 & 2 & 3 & 3 \\
\hline $\begin{array}{l}\text { Learning computer would improve the } \\
\text { presentation of work in class }\end{array}$ & 188 & 3.6 & 0.7 & 3 & 4 & 4 \\
\hline $\begin{array}{l}\text { Teachers use the multimedia technology (use } \\
\text { computers and other materials) }\end{array}$ & 187 & 3 & 0.9 & 3 & 3 & 4 \\
\hline $\begin{array}{l}\text { There is provision of professional support } \\
\text { through the internet (online learning) }\end{array}$ & 188 & 2.5 & 1.3 & 2 & 3 & 4 \\
\hline Students learn better through computers & 184 & 2.8 & 1 & 2 & 3 & 4 \\
\hline $\begin{array}{l}\text { Computers increase the level of software } \\
\text { applications use e.g. word, access, excel }\end{array}$ & 189 & 3.4 & 0.8 & 3 & 4 & 4 \\
\hline I have improved my skills on computers & 189 & 2.8 & 1.3 & 2 & 3 & 4 \\
\hline
\end{tabular}

When the responses to all items on student perception to ICT experience in teaching and learning were combined, $61 \%$ of the participants either agreed or strongly agreed with at least $75 \%$ of the items as shown in Figure 3. 


\section{Figure 3: Overall ICT knowledge levels among KMTC students}

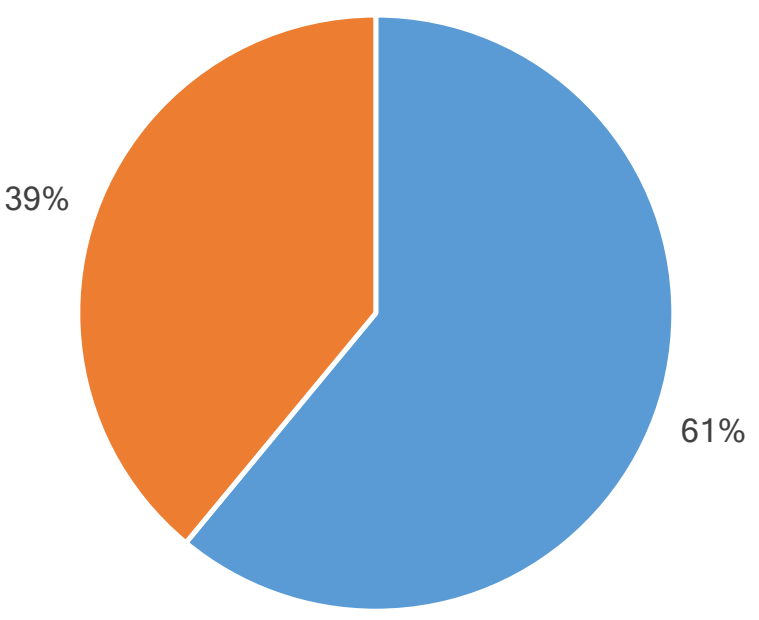

- Strongly agree/ agree with at least $75 \%$ of items $\quad$ Strongly agree/ agree $<75 \%$ of items

\section{ICT knowledge and student characteristics}

There was a significant association between knowledge and perception of ICT and participants sex $(p=0.001)$, Table 3 . Females were more likely to have positive responses compared to males (72.3 versus 49.9\%). Access point was also associated with perception $(p=0.005)$. Accessing computers in the computer lab was associated with higher Likert scale responses. 
Table 3: Student knowledge or perception of ICT in teaching and learning and individual characteristics

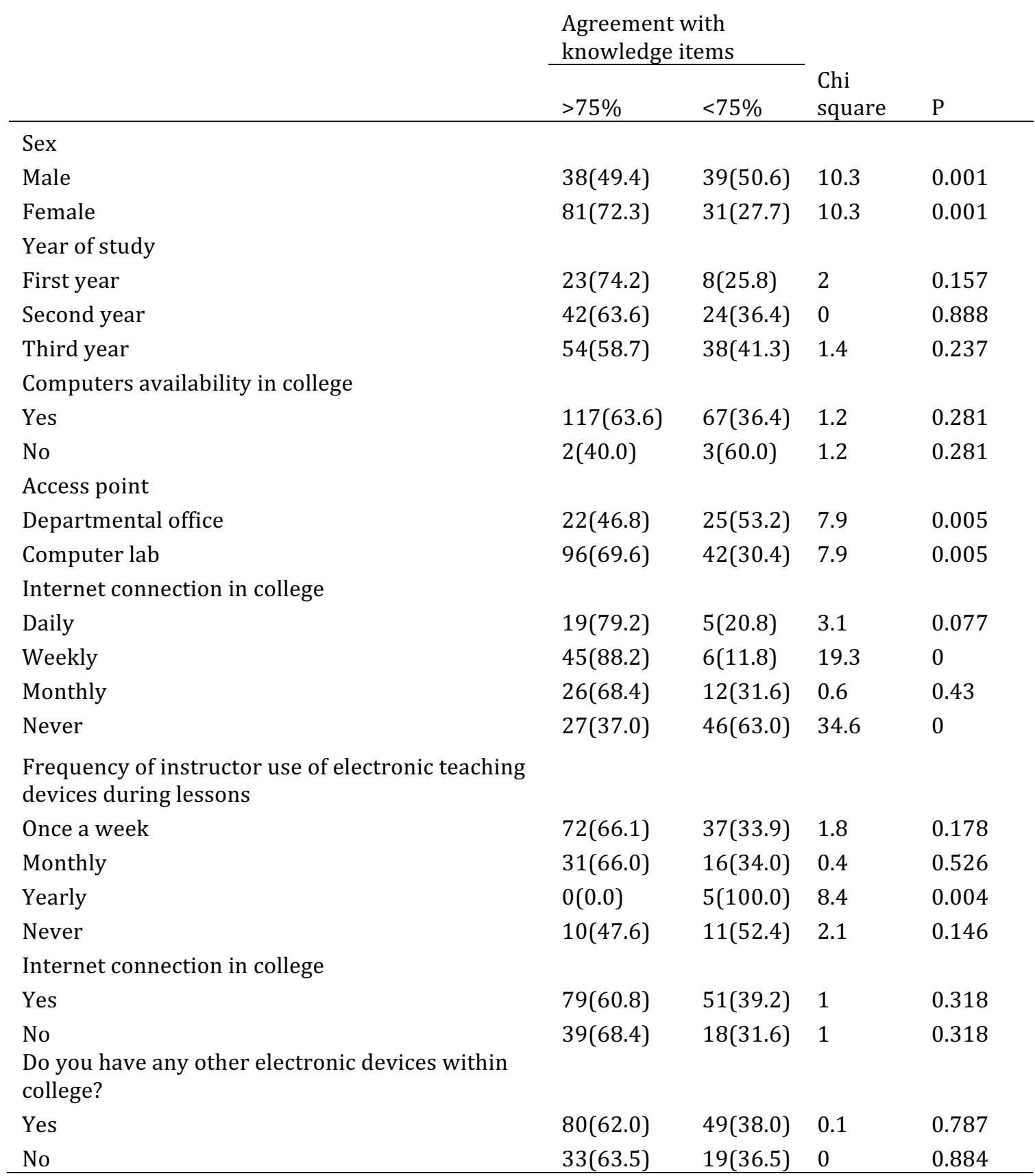


Frequency of computer use and perceived role of computers in teaching and learning

\begin{tabular}{|c|c|c|c|c|c|}
\hline & Daily & Weekly & Monthly & Never & \multirow[b]{2}{*}{$\begin{array}{l}\text { K-Wallis } \\
\text { P value }\end{array}$} \\
\hline & $\begin{array}{l}\text { Median } \\
\text { (IQR) }\end{array}$ & $\begin{array}{l}\text { Median } \\
\text { (IQR) }\end{array}$ & $\begin{array}{l}\text { Median } \\
\text { (IQR) }\end{array}$ & $\begin{array}{l}\text { Median } \\
\text { (IQR) }\end{array}$ & \\
\hline The college promotes computer use & $4(3-4)$ & $3(3-4)$ & $3(2-4)$ & $2(1-3)$ & 0.000 \\
\hline $\begin{array}{l}\text { There is increased instructional materials in the } \\
\text { internet }\end{array}$ & $3(3-4)$ & $3(2-4)$ & $3(2-4)$ & $2(1-3)$ & 0.006 \\
\hline $\begin{array}{l}\text { Learning computer would improve the } \\
\text { presentation of work in class }\end{array}$ & $4(3-4)$ & $4(3-4)$ & $4(3-4)$ & $4(3-4)$ & 0.629 \\
\hline $\begin{array}{l}\text { Teachers use the multimedia technology (use } \\
\text { computers and other materials) }\end{array}$ & $4(3-4)$ & $3(3-4)$ & $3(3-4)$ & $3(2-3)$ & 0.002 \\
\hline $\begin{array}{l}\text { There is provision of professional support } \\
\text { through the internet (online learning) }\end{array}$ & $3(2-4)$ & $3(2-4)$ & $3(2-4)$ & $2(1-3)$ & 0.020 \\
\hline Students learn better through computers & $3(2-4)$ & $3(2-4)$ & $3(2-4)$ & $3(2-4)$ & 0.600 \\
\hline $\begin{array}{l}\text { Computers increase the level of software } \\
\text { applications use e.g. word, access, excel }\end{array}$ & $4(3-4)$ & $4(3-4)$ & $4(3-4)$ & $3(3-4)$ & 0.331 \\
\hline I have improved my skills on computers & $4(3-4)$ & $4(3-4)$ & $4(3-4)$ & $2(1-3)$ & 0.000 \\
\hline
\end{tabular}

During [4]. Summative assessment, he showed that students could attain a desired standard of knowledge if a lecture series was replaced by the CAL program; that the program was userfriendly, even for students with little or no computer experience; and that most students considered it to be a useful learning resource. More than half the students were concerned about using CAL to replace human instruction. It is significant that students were particularly impressed by aspects of the program that could not be duplicated by a book; the interactive nature of the learning process and the ability to rotate the diagnostic casts. This highlights the need for CAL programs to use the full potential of computer capability, rather than merely replicate a textbook on a screen [4].

There was a significant association between knowledge and perception of ICT and participants sex $(p=0.001)$. $P$ value is used to help tell if the null hypothesis is true of false. When the $p$ value is less than 0.05 , this means that there is a statistical association between the observed measurements and we accept the null hypothesis. When the $\mathrm{p}$ value is greater than 0.05 , it means that there is no statistical significance and we reject the null hypothesis and go with the alternative hypothesis. Females were more likely to have positive responses compared to males (72.3 versus 49.9\%). Access point was also associated with perception $(\mathrm{p}=0.005)$. Accessing computers in the computer lab was associated with higher Likert scale responses. The perception of CAL among the students was closely associated with how much the students access the CAL and their knowledge on computers at KMTC

[9], postulated in his findings that Computer assisted learning programs were interactive and enable students to control the pace and sequence of their learning. Silverman and Casazza, (2010). Added that during the learning process, students are presented with specific tasks and must master them before going to the next level. In the drill and practice of computer assisted learning, the pace and number of trials to reach mastery varies from student to student. In Kenya, few studies have document the impacts of CAL on classroom practice. In a study on enhancement of science performance through computer-assisted instruction among selected medical learners in Kenya, [4] noted that the improvement in medical practical performance by the experimental group resulted from the application of CAL lessons that the instructional methods used by teachers influence the performance of the learners. Although [5] also distinguished that the teaching approach that a teacher adopts was one factor that may have affect students' achievement, and therefore use of an appropriate teaching approach is critical to the successful teaching and learning. 


\section{CONCLUSION}

Based on the results and discussions, among the main problems that key informants described during the study, regardless of the fact that there was a significant association between knowledge and perception of ICT and participant's gender, female students had more access to CAL facilities as compared to the male students. Hence the female students at KMTC had more knowledge as compared to the male students with regards to CAL

\section{ACKNOWLEDGMENTS}

First, I am indebted to the Almighty GOD for all the blessings, abilities and wisdom He has been showering me and for being with me throughout the study. It has been an exciting and instructive study period in the Jomo Kenyatta University of Agriculture and Technology and I feel privileged to have had the opportunity to carry out this study as a demonstration of knowledge gained during the period of study for my Master's degree. With these acknowledgments, I want to thank all those who in one way or another, directly or indirectly played a role in the realization of this research project. I cannot mention all of them; therefore earnestly thank them all equally. I am deeply obliged to my Research assistants Mutiso Nicholas Kivungi and Dr. Phillip Ayiecko for their exemplary guidance and support without whose help; this project would not have been a success, Finally, yet importantly, I take this opportunity to express my deep gratitude to my loving Father Isaac Omambia, my Mother Anna Omambia, my beloved wife Gloria Chepkemoi, Sons Fahim Salim, Michael Salim and daughter Shayna Salim for whom who have and are a constant source of motivation not forgetting their never ending support, encouragement and love during this project.

\section{References}

Congram, G. (2015). "Computer-based training simplifies safety compliance". Pipeline and Gas Journal, 222, 52-54

Jwayyed S, Stiffler K, Wilber T, Southern A, Weigand J, Bare R, and Gerson W (2015). Technology-assisted education in graduate medical education: a review of the literature. J Surg Educ. 2015 Nov-Dec; 72(6):1145-57. doi: 10.1016/j.jsurg.2015.05.008. Epub 2015 Jun 22.

Ministry of Education Science and Technology Sessional Paper, (2012).Nairobi; Government printers.

Samuel, N. J. (2012). Enhancement of Science Performance through Computer-Assisted Instruction among Selected college School Learners in Kenya . Unpublished MED in the School of science University, of Nairobi

Wambugu, P. W., and Changeiywo, J. M. (2015). Effects of E- Learning Approach on Medical colleges Achievement. Eurasia Journal of Computer, Science, and Technology Education, 4(3), 293-302

Rayne, R., \& Baggott, G. (2004). Computer-based and computer-assisted tests to assess procedural and conceptual knowledge.

Lau F, Bates J; A review of e-learning practices for undergraduate medical education. Journal of medical systems, 2004; 28(1): 71-87

Bayraktar, S. (2009). A Meta-analysis of the Effectiveness of Computer-Assisted Instruction in Science Education. Journal of research on technology in education, 34(2).

Driscoll, M. P. (2011). Psychology of learning for instruction. Needham Heights, MA: Allyn Ed.). Upper Saddle River, NJ: Merrill/Prentice Hall.

J.S., Armstrong (2012). "Natural Learning in Higher Education". Encyclopedia of the Sciences of Learning. Heidelberg: Springer

Ruiz JG, Mintzer MJ, Leipzig RM; The impact of e-learning in medical education. Academic medicine, 2006; 81(3):207-212 